M. R. BOND AND LIONEL WOLMAN: NEUROTOXICITY OF ETHOGLUCID

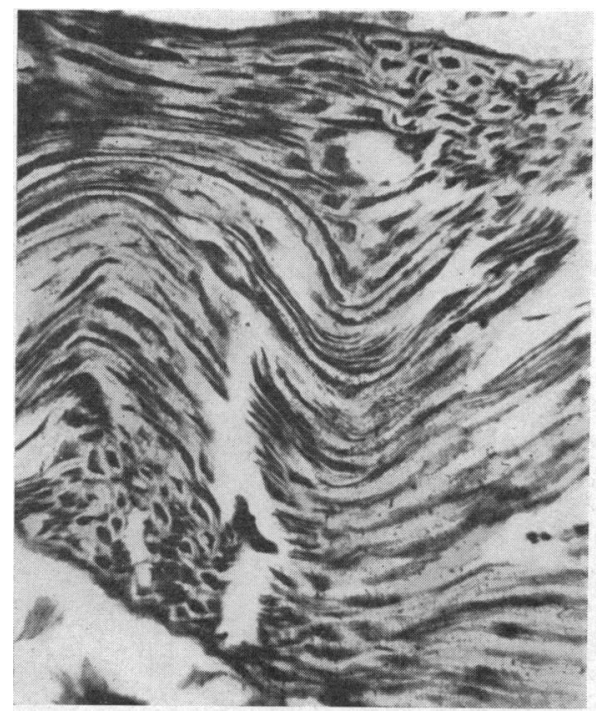

Fig. 1.-Longitudinal section of femoral nerve showing ballooned axis cylinders; 45 minutes after arterial injection of ethoglucid. (Silver.

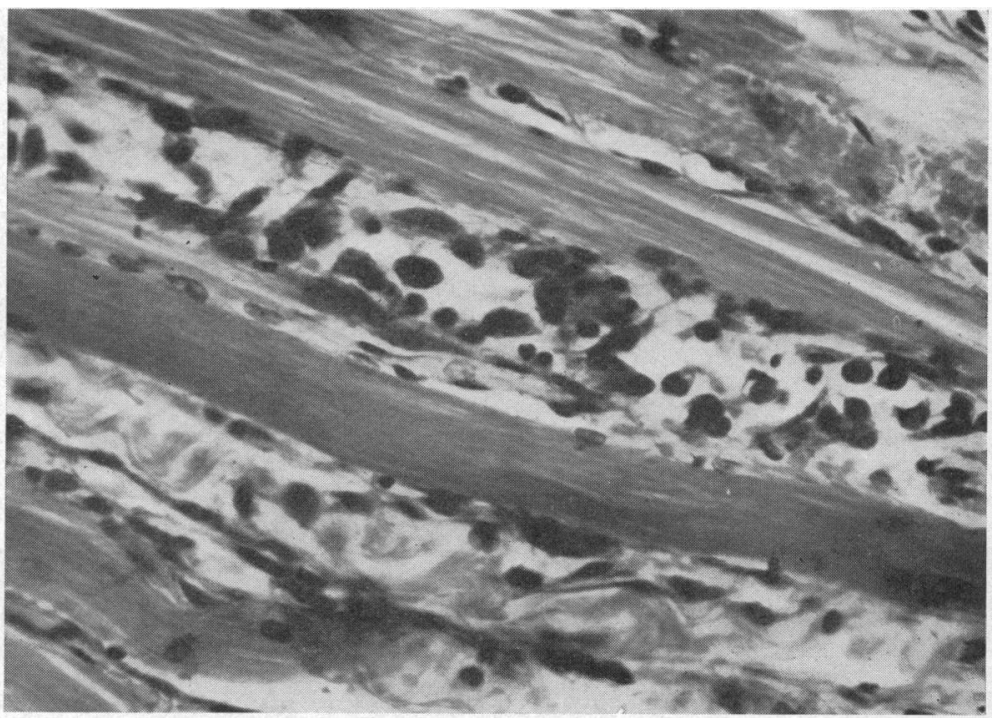

Fig. 2.-Necrotic muscle fibres four days after injection. (H. and E. $\times 310$.)
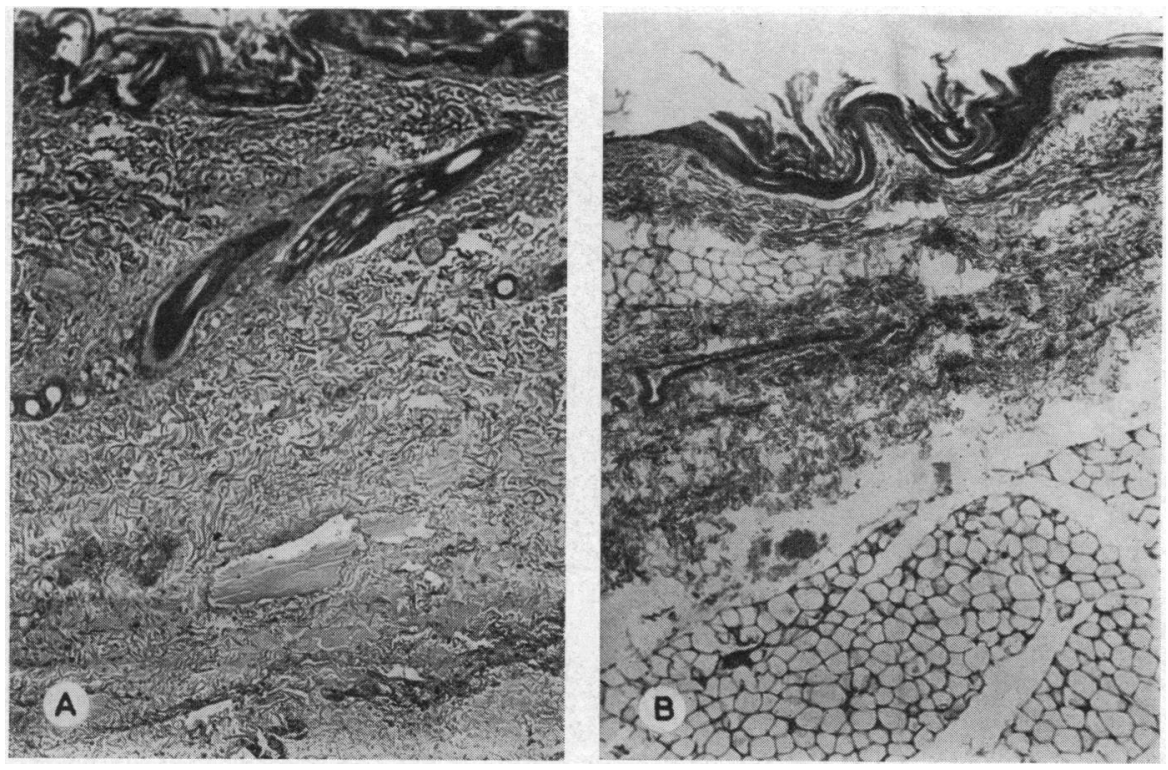

FIg. 3.-Sections of skin of dog. (A)

Four days after injection, showing serous subcutaneous exudate. (B) Normal healthy animal for comparison. (H. and E. $\quad \times 38$.

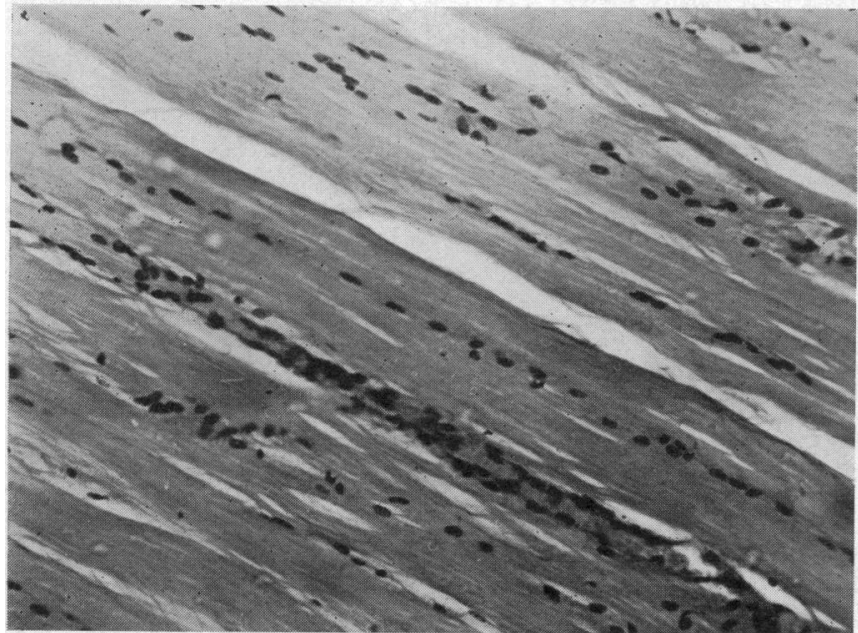

FIG. 4.-Muscle fibres showing neural atrophy eight days after injection. (H. and E. $\times 186$.)

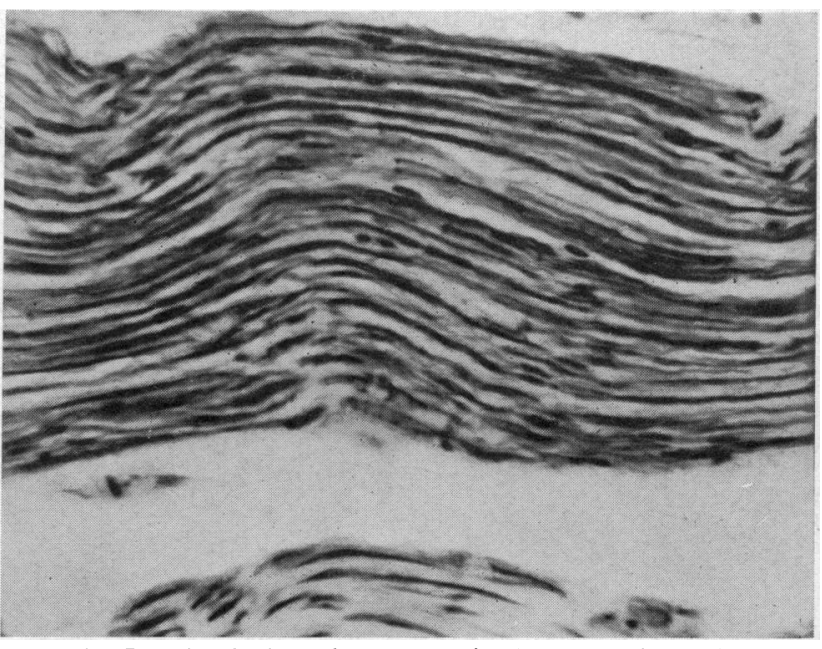

FIG. 5.- - Longitudinal section of proximal part of femoral nerve showing a few swollen axis cylinders; eight days after injection. 


\section{R. BOND AND LIONEL WOLMAN: NEUROTOXICITY OF ETHOGLUCID}

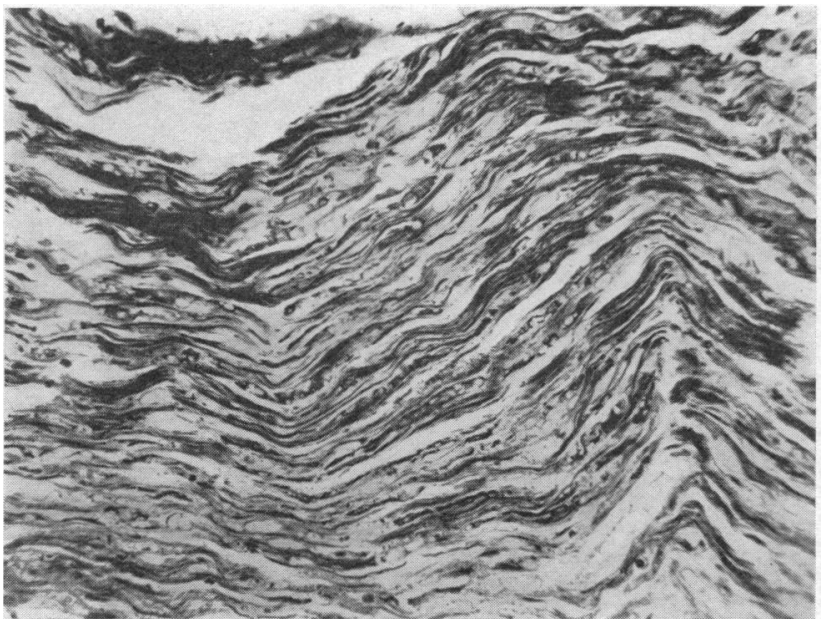

FIG. 6.-Distal part of same nerve as in Fig. 5 eight days after injection, showing severe degeneration and fragmentation of axons. (Silver. $\times 180$.)

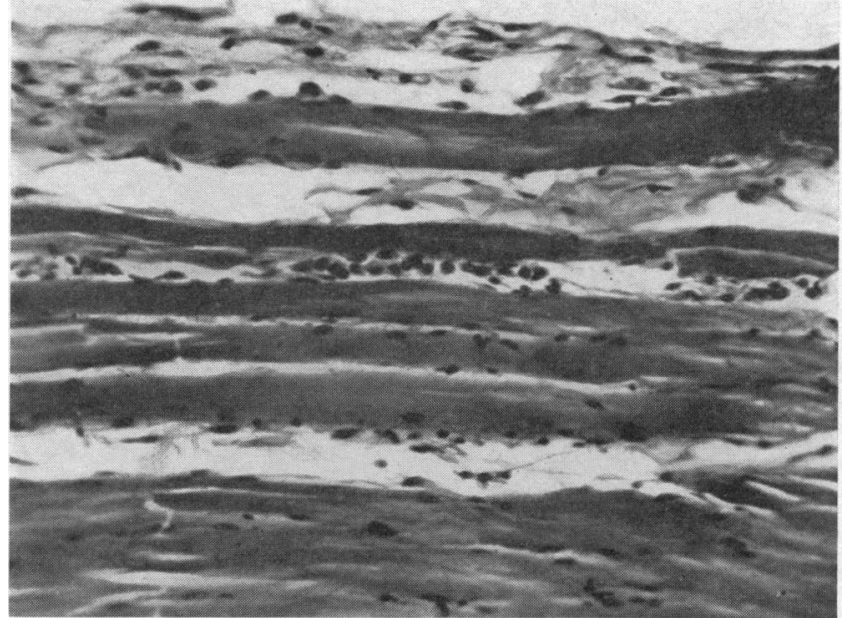

FIG. 7.-Focal necrotic myositis 10 days after injection. (H. and E. $\times 186$.

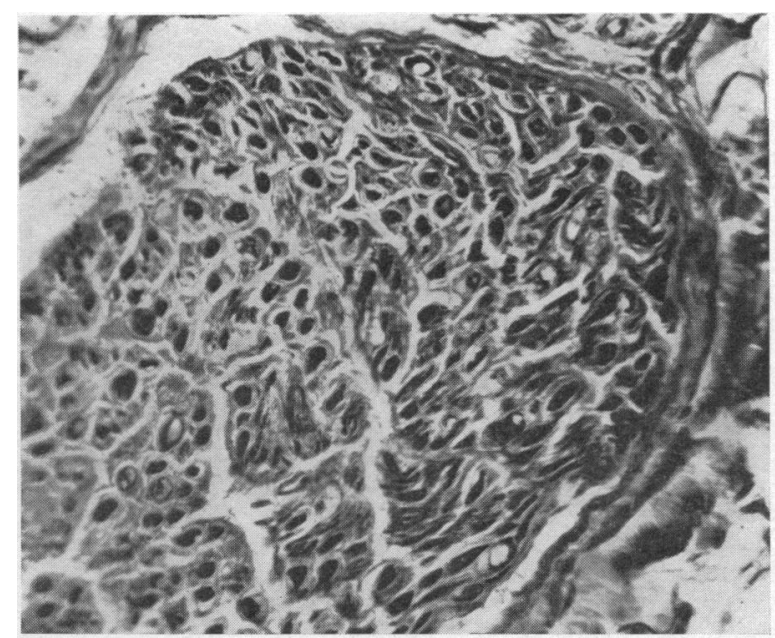

FIG. 8. - Transverse section of femoral nerve 10 days after injection, showing swollen vacuolated axis cylinders. (Silver.

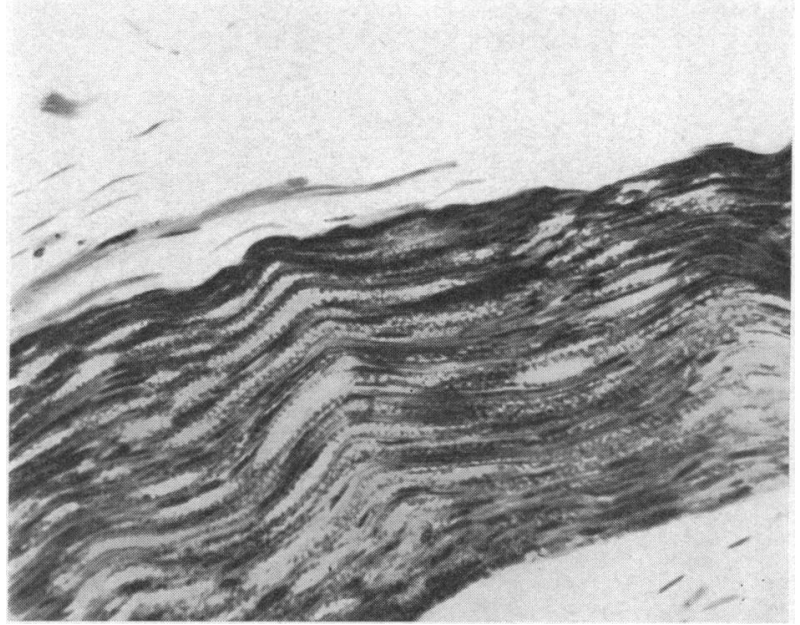

FIG. 9.-Longitudinal section of femoral nerve 14 days after injection, showing vacuolated myelin sheaths. (Myelin.

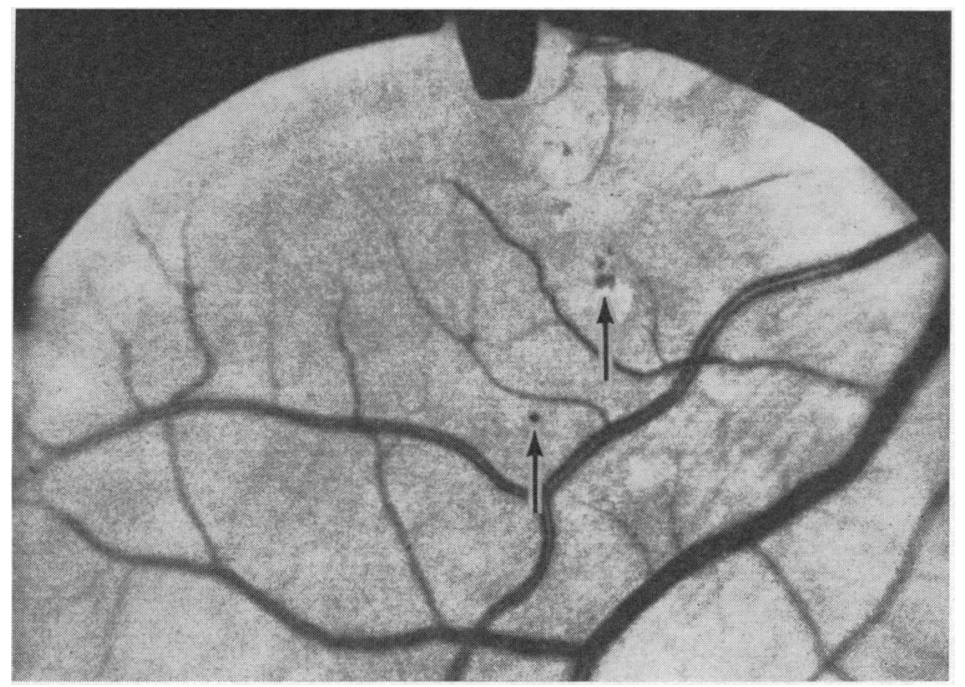

Enlargement of right inferior temporal quadrant of retinal photograph showing several microaneurysms (arrowed). 
We wish to acknowledge the help given by Dr. P. Waller and the staff of the Routine Biochemistry Department, Sister Fraser, Nurse Cogger, and Mrs. N. Higgins.

\section{REFERENCES}

Bernstein, D. S., Guri, C., Cohen, P., Collins, J. J., and Tamvakopoulos, S. (1963). ₹. clin. Invest., 42, 916.

Cannell, W. A. (1960). Medical and Dental Aspects of Fluoridation. Lewis, London.

Geall, M. G., and Beilin, L. J. (1964). Brit. med. 7., 2, 355.

Peters, J. H.' (1948). Amer. F. med. Sci., 216, 278.
Purves, M. J. (1962). Lancet, 2, 1188.

Reifenstein, E. C., Albright, F., and Wells, S. L. (1945). F. clin. Endocr., 5, 367.

Rich, C., and Ensinck, J. (1961). Nature (Lond.), 191, 184.

Roholm (1962). Clin. Res., 10, 118.

Roholm, K. (1937). Fluorine Intoxication: A Clinical Hygienic Study. Lewis, London.

Sollman, T. (1957). A Manual of Pharmacology, 8th ed. Saunders, Philadelphia.

Sorsby, A., and Harding, R. (1960). Brit. F. Ophthal., 44, 213.

Waldbott, G. L. (1963). Acta med. scand., 174, Suppl. No. 400, p. 5.

Walker, P. G., and Collins, Judith A. (1963). In Bone Metabolism in Relation to Clinical Medicine, edited by H. A. Sissons, p. 55 . Pitman Medical, London.

\title{
Experimental and Clinical Observations Concerning the Neurotoxicity of Ethoglucid
}

\author{
M. R. BOND,* M.B., CH.B. ; LIONEL WOLMAN, $\dagger$ M.D., PH.D., M.R.C.P., D.P.M.
}

[With Special Plate]

Brit. med. F., 1965, 1, 1161-1163

In a recently reported clinical trial of a new alkylating agent, ethoglucid (triethyleneglycol diglycidyl ether; Epodyl), used in the treatment of advanced malignant disease, attention was drawn to the rapidity with which relief from pain occurred after administration of the drug by intravenous or intra-arterial injection (Bond et al., 1964). In addition, the observed toxic effects of the agent included temporary, and occasionally permanent, damage to motor and sensory nerves. A similar account of the neurotoxicity of ethoglucid has been reported by Westbury $(1962,1963)$. Comparable effects have been observed with the alkylating agent nitrogen mustard. Mahaley and Woodhall (1962) demonstrated that exposure of peripheral nerve tissue to high concentrations of this substance led to neurotoxic changes characterized by destruction of myelin organization and fragmentation of axis cylinders. This neurotoxic property has been utilized by Hanna et al. (1963) in the treatment of pain caused by cancer of the head and neck, following several previous observations on its pain-relieving effects (Sholes, 1960 ; Woodhall et al., 1960).

With these exceptions, the neurotoxicity of alkylating agents has received little attention in the literature, and there is only scant information concerning either their mode of action or their use solely for the relief of pain in advanced malignant disease. It is therefore considered of interest to undertake an experimental study, using ethoglucid, to determine more precisely the nature of this effect and its histopathological basis. The relation of any morphological changes produced to the time of administration of the agent might thus be studied and correlation of the experimental findings with clinical observations made.

\section{Material and Methods}

In order to eliminate any effects on the peripheral nervous system which a malignant tumour might produce, the experiments were performed on 10 healthy mongrel dogs weighing between 10 and $15 \mathrm{~kg}$. Of these animals, two served as controls, and from them pieces of normal nerve, muscle, and skin were obtained for comparison with similar material taken from identical sites in the remaining eight receiving the drug.

Each animal for infusion was first anaesthetized, after which the femoral vessels of one hind limb were exposed through a short incision. A fine-bore polyethylene catheter, or a Seldinger cannula, was then introduced into the femoral artery, the tip being advanced to the bifurcation of the common iliac artery. Ethoglucid in a dose of $100 \mathrm{mg} . / \mathrm{kg}$. body weight, diluted in $10 \mathrm{ml}$. of $0.9 \%$ sodium chloride solution, was infused into the artery over a period of three to four minutes. The infusion apparatus was then flushed with normal saline solution, withdrawn, and bleeding from the vessel controlled prior to suture of the skin incision. After injection the animals were sacrificed at intervals of 45 minutes, 24 and 48 hours, and 4, $8,10,14$, and 28 days. At post-mortem examination the femoral nerve, a section of adductor muscle supplied by the nerve, and the overlying skin were removed from the infused limb for histological examination.

The tissue was embedded in paraffin, prior to which a small amount was used in the preparation of frozen sections. The paraffin blocks were serially sectioned and stained by haematoxylin and eosin, phosphotungstic acid haematoxylin, thionine, Loyez, Gross-Bielschowsky, Scharlach R, and osmic acid. The nerve and muscle were sectioned both transversely and longitudinally.

\section{Results}

After operation a limp was detected until the sixth or seventh day in all animals surviving eight days or longer. No evidence of permanent motor-nerve damage was observed and gross sensory disturbances were not detected in any case.

\section{Histology}

45 Minutes.-The earliest change detected was an irregular swelling of several of the axis cylinders in the femoral nerve (Special Plate, Fig. 1). The myelin sheaths appeared intact and the Schwann-cell nuclei and vasa nervorum showed no abnormality. The muscle and skin were normal.

24 Hours.-The muscle contained an occasional small group of necrotic fibres with cellular increase due to polymorphs and

\footnotetext{
* University Department of Surgery, Royal Infirmary, Sheffield. Present Address: Whiteley Wood Clinic, Woofindin Road, Sheffield 10, to † Department of Neuropathology, Royal Infirmary, Sheffield.
} 
lymphocytes. Several nerve fibres showed irregular swelling and ballooning of axis cylinders with pallor of staining and swelling of myelin sheaths. No interstitial inflammatory reaction was seen and the Schwann-cell nuclei appeared intact. The vasa nervorum were normal and patent. No abnormality was seen in the skin, but in the deeper part of the subcutaneous fat were several necrotic foci containing numerous polymorphs.

48 Hours.-Several groups of necrotic muscle fibres were replaced by lymphocytes, polymorphs, and a few histiocytes. Scattered swollen irregular axis cylinders, some of which appeared ballooned, were present in the nerve. The myelin sheaths of these fibres were fragmented or vacuolated. The epineurial fat around the nerve contained a moderately severe polymorph reaction, especially round vessels, but the vasa nervorum appeared to be normal. The skin showed a marked serous exudate in the fatty connective tissue beneath the dermis with a few lymphocytes cuffing some of the vessels.

Four Days.-The muscle showed a patchy necrotic myositis, with scattered isolated muscle fibres or small groups of fibres being replaced by masses of polymorphs, lymphocytes, and occasional macrophages (Special Plate, Fig. 2). The intervening fibres were intact and of normal appearance. The femoral nerve showed numerous scattered fibres with irregularly swollen axis cylinders and myelin sheaths which were beaded, pale-staining, and fragmented. Schwann-cell nuclei seemed to be normal. The dermis and subcutaneous fatty connective tissue were oedematous, being distended with a pale eosinophilic serous exudate (Special Plate, Fig. 3), which also filled the perivascular spaces and surrounded the bundles of nerve fibres. Bloodvessels in skin, nerve, and muscle were apparently normal.

Eight Days.-Scattered muscle fibres or small groups of fibres showed early neural atrophy with marked increase in subsarcolemmal nuclei (Special Plate, Fig. 4). The intervening fibres seemed to be normal. The femoral nerve contained scattered globules of free fat in frozen sections. Several ballooned axis cylinders were seen in the proximal part of the femoral nerve (Special Plate, Fig. 5), while distally the changes in axis cylinders were very much more severe with fragmentation and marked irregularity and tortuosity of fibres (Special Plate, Fig. 6). Some of the Schwann-cell nuclei were shrunken and hyperchromatic. The blood-vessels in skin, nerve, and muscle appeared normal. The subcutaneous exudate had almost disappeared.

Ten Days.-Several necrotic muscle fibres were present in the adductor (Special Plate, Fig. 7). These were replaced by chains of macrophages with some lymphocytes. Swollen axis cylinders which appeared ballooned in longitudinal section and vacuolated in transverse section (Special Plate, Fig. 8) were present in the femoral nerve with demyelination of the affected fibres. A few shrunken hyperchromatic Schwann-cell nuclei were seen. Blood-vessels in the nerve seemed normal, but there was a lymphocytic reaction in the epineurial and perineurial connective tissue. The subcutaneous fat contained scattered lymphocytes and histiocytes.

14. Days.-The adductor muscle contained necrotic fibres, in which were numerous lymphocytes and macrophages and also occasional fibres showing marked increase in subsarcolemmal nuclei owing to neural atrophy. Occasional nerve fibres showed demyelination (Special Plate, Fig. 9) with irregular swelling or ballooning. Blood-vessels in skin, nerve, and muscle appeared normal.

28 Days.-Only an occasional small atrophic muscle fibre with increase in subsarcolemmal nuclei was present. The nerve contained some beaded nodular axis cylinders with an occasional vacuolated demyelinated fibre. The vasa nervorum were normal. A few scattered lymphocytes were present in the surrounding epineurial connective tissue. The skin showed increased cellularity in the subcutaneous tissue owing to lymphocytes and fibroblasts.

\section{Discussion}

The damage to nerve tissue caused by ethoglucid seems to be a direct toxic effect of the drug, not involving damage to the vasa nervorum. The speed with which detectable histological changes in nerve fibres follow infusion is rapid and accords well with the clinical observation that relief of pain, together with other symptoms of nerve damage, occurs within 24 to 48 hours of infusion of the agent.

Evidence that small finely myelinated fibres in nerve bundles are more susceptible to damage than the larger more heavily myelinated fibres was not forthcoming. Specificity of the drug for motor or sensory nerves was not established but the results of the animal experiments suggest that damage to both occurs. This is in agreement with the histological findings reported with other pain-relieving agents such as phenol given intrathecally (Baxter and Schacherl, 1962; Berry and Olszewski, 1963; Stewart and Lourie, 1963 ; Smith, 1964), and with other chemotherapeutic agents applied topically, by subepineurial injection or by vessel-perfusion (Woodhall et al., 1962). It also correlates with clinical results where all forms of nerve damage have been observed, most frequently with pain relief. Other forms of sensory loss and motor-nerve lesions are less common. Recovery from the neurotoxic effect of the drug was clearly demonstrated. This is again in agreement with clinical observations which indicate that persistence of motor or sensory nerve damage, apart from that to pain fibres, is uncommon. Permanent damage does occur to a limited degree, as demonstrated experimentally by the development of neural atrophic changes in a small number of muscle fibres. However, unless present on a large scale such changes would not be detected clinically.

The explanation for the random way in which damage to nerve fibres occurs is not clear, but it is reasonable to assume that this is a reflection of variations both in the concentration of the drug in the blood-stream and in the anatomical distribution of the smaller blood-vessels.

In addition to neurotoxic effects, ethoglucid was also responsible for the production of limb oedema and myositis. The oedema was associated with a serous exudate in the subcutaneous fat, which was recognized within 48 hours, increased in amount after four days, and had almost disappeared by eight days. Although oedema is often noted in the infused area during treatment of cancer of the head and neck, symptoms of myositis are not observed clinically as might be expected from the histological studies presented in this paper. This may be due to the fact that only an occasional fibre or a few small groups of muscle fibres were involved.

Concerning the mode of action of these chemotherapeutic agents on peripheral nerves, Woodhall et al. (1962) showed that blood-vessels, myelin, and axis cylinders were all damaged in the canine sciatic nerve by nitrogen mustard. In a recent study of the ultrastructural changes with the electron microscope, Boone and Woodhall (1964) investigated the primary morphological effects and site of action following subepineurial injection of nitrogen mustard. The earliest change observed was clumping of chromatin in the nucleus of the Schwann cell, and this was regarded as the primary effect. It was followed by degeneration of the entire Schwann cell, including the myelin, and axis-cylinder degeneration. The pain-conducting $C$ fibres were the first axis cylinders to degenerate, and this was attributed to the fact that they are embedded in Schwann cytoplasm and covered by only one layer of plasma membrane, whereas A and $\mathrm{B}$ fibres have many wrappings of plasma membrane around their axon. In the present experiments the ethoglucid was given by intra-arterial infusion and its primary effect as observed by light microscopy was on axis cylinders. The nature of the agent, dosage, and method of administration may account for these differing effects, but it seems likely that if axis cylinders are the site of primary damage then the areas protected by welldeveloped thick myelin sheaths would be less likely to sustain permanent irreversible damage. Thus a possible explanation for 
the more lasting effects of pain relief is suggested, even though all sizes of fibres sustain some damage.

\section{Summary and Conclusions}

The neurotoxicity of ethoglucid given by arterial perfusion has been investigated in dogs in order to study the histological basis of the various effects noted in clinical practice.

A direct toxic effect on nerve fibres of all types was found, and, in addition, damage to muscle and skin in the infused area was observed. A greater proportion of these effects appears to be reversible.

The results support the hypothesis that relief of pain is primarily the result of damage to pain-nerve fibres, which occurs rapidly after administration of the drug, but they offer no definite explanation why this relief tends to persist while other neurological effects subside, although a theoretical possibility is discussed.

The value of ethoglucid in the treatment of advanced malignant disease depends on its pain-relieving effect as well as its cytotoxic properties.
Our thanks are due to Mr. F. D. Naylor for his assistance with the experiments and to $\mathrm{Mr}$. $\mathrm{K}$. Horton for preparing the histological sections. The ethoglucid used in this study was supplied by I.C.I., to whom we are grateful. The work was carried out while one of us (M. R. B.) was in receipt of a British Empire Cancer Campaign Research Grant, and for this support we are indebted.

\section{REFERENCES}

Baxter, D. W., and Schacherl, U. (1962). Canad. med. Ass. 7., 86, 1200. Berry, K., Olszewski, J. (1963). Neurology (Minneap.), 13, 152.

Bond, M. R., Clarke, S. D., and Neal, F. E. (1964). Brit. med. F., 1, 951. Boone, S. C., and Woodhall, B. (1964). \%. surg. Res., 4, 413.

Hanna, D. C., Gaisford, J. C., and Goldwyn, R. M. (1963). Amer. Y. Surg., 106, 783.

Mahaley, M. S., and Woodhall, B. (1962). Cancer Chemother. Rep., 16, 543.

Sholes, D. M. (1960). Amer. 7. Obstet. Gynec., 80, 481.

Smith, M. C. (1964). Brit. F. Anaesth., 36, 387.

Stewart, W. A., and Lourie, H. (1963). Ұ. Neurosurg., $20,64$.

Westbury, G. (1962). Proc. roy. Soc. Med., 55, 643.

- (1963). Ibid., 56, 655 .

Woodhall, B., Mahaley, M. S., jun., Boone, S., and Huneycutt, H. (1962). f. surg. Res., 2, 373.

Pickrell, K. L., Georgiade, N. G., Mahaley, M. S., jun., and Dukes, H. T. (1960). Ann. Surg., 151, 750 .

\title{
Improving the Reliability of the Rebreathing Method for Measuring Mixed Venous $\mathbf{P C O}_{2}$
}

\author{
SIMON GODFREY,* M.B., M.R.C.P.
}

Brit. med. F., 1965, 1, 1163-1165

A rebreathing method for measuring mixed venous $\mathrm{PCO}_{2}$, suitable for clinical use, was described by Campbell and Howell (1960a, 1960b, 1962), employing a principle probably first introduced by Plesch (1909). The present paper is based upon experience gained in the everyday use of the method, and suggests a modification to obtain the maximum accuracy with minimum discomfort to the patient.

Briefly, the standard procedure advised by Campbell and Howell (1962) consists of a first stage of rebreathing from a bag of oxygen of not more than two or three times the tidal volume for a period of 90 seconds. This usually produces a bag $\mathrm{PCO}_{2}$ a little above mixed venous $\mathrm{PCO}_{2}$ (Campbell and Howell, $1960 \mathrm{~b})$. After a rest of at least two minutes the second stage consists in rebreathing the prepared mixture for 20 seconds. During this second stage small differences between mixed venous and bag $\mathrm{PCO}_{2}$ are usually eliminated. In their papers Campbell and Howell have commented that various changes in the procedure may be necessary with some patients, but these manœuvres are rarely employed in normal clinical practice.

The main problems which have been encountered with the standard method are: (1) many subjects become very uncomfortable after 90 seconds of rebreathing from a small bag, however persuasive the operator; and (2) although Campbell and Howell have suggested a checking procedure it is not

* Medical Unit, Brompton Hospital, London. Present address : Department of Physiology, London Hospital Medical College, London E.1. routinely performed, and with inexperienced operators gross errors have been found through some fault in technique which has escaped notice.

In order to overcome these difficulties various modifications of the technique have been examined. In particular, the need for an arbitrary time for the first stage has been queried, and a routine checking procedure has been sought.

Personal experience showed that during the first stage a stimulus to breathing was noticed when the bag $\mathrm{PCO}_{2}$ was close to arterial blood $\mathrm{PCO}_{2}$. It therefore seemed that the discomfort during rebreathing was probably part of a $\mathrm{CO}_{2}$ response. Preliminary experiments showed that if the rebreathing was terminated about 10 to 15 seconds after the response was noted the bag $\mathrm{PCO}_{2}$ was a little above mixed venous $\mathrm{PCO}_{2}$.

The second stage of the rebreathing procedure can be regarded as the "fine adjustment" of a bag $\mathrm{PCO}_{2}$ which is already close to mixed venous levels. The gas is rebreathed for 20 seconds, during which time any differences between bag and mixed venous $\mathrm{PCO}_{2}$ should be eliminated, before much blood with an elevated $\mathrm{PCO}_{2}$ has had time to recirculate. In fact, recirculation of blood does mean that the bag $\mathrm{PCO}_{2}$ after 20 seconds is a little too high, but this is of no clinical significance. The only way to obtain a completely accurate result is to scan the record from a rapid $\mathrm{CO}_{2}$ analyser and look for a plateau in the $\mathrm{CO}_{2}$ concentrations of gas passing back and forth from mouth to bag (Collier, 1956). A comparison of the $\mathrm{PcO}_{2}$ obtained after 20 seconds of rebreathing from a bag close to 